

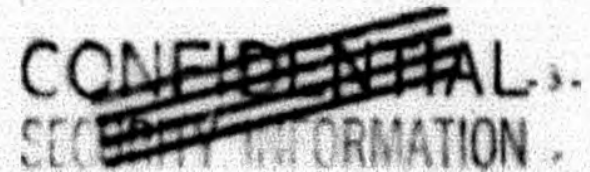

UCRL.2294

\title{
NEUTRON TOTAL CROSS SECTION FOR BISMUTH AND URANIUM BETWEEN 45 AND 160 MEV
}

\author{
w. 1. Linlor and B. Ragent
}

Radiation Laboratory, Department of Phyoica University of California, Berkeley. California

Neutron total cross sections for biemuth and uranium have been measured in a good geometry tranomisoion experiment, using a time-of-fight instrumeatation. 1,2 The source of neutrons was the siripped deuteron beam: of the 184-inch eynchrocyclatron. The results are ohown in Fig. 1. Uncer. tainties are shown in terms of otandard deviations, due to counting otatistics only, and $w$ energy channel width.

The diotribution of values indicaten a "dip" in cross eection in the vieinity of 60 Mev for the two elements, simslar to resulto firot obtained by Tayior and Wood for lead. $3,4,5$

Absolute values of the croos section may be in error by a conotant eotimated to be $\neq 0.2$ barn because of beam intenoity variations. Inasnuch as ouch a conotant would be added to all the point, for an element, it would not affect the variation of crous section with energy.

The energy scale was calibrated by time-of-fight of gamma rays. The time-of-flight of a neutron or photon could be meacured with a probable error of $\star 0.2 \times 10^{-8}$ secondo, including the effect of neutron production time (this leade to a resolution of $5 \times 10^{-11}$ secondo per meter at the firgbt diotance of 43.7 meters). At 90 Mev the absolute value of the quoted energy seems to be in error by not more than $\neq 2$ Mev.

We wilh to thank Prof. H. F. York for ouggesting this technique and Prof. L. W. Alvarez, under whose guidance this work was carried out, for valuable ouggeations; also James Vale, Lloyd Hauser and the cyclotron criw for much cooperation. Thanke are due also to Robert Silver and John Leahy whose help at times of rune was particularly welcome, and to Vern. Ogren and Don Paxon, both of whom rendered expert electronics assiotance in many ways.

Thin work was oponsored by the United States Atomic Energy Com:miesion.

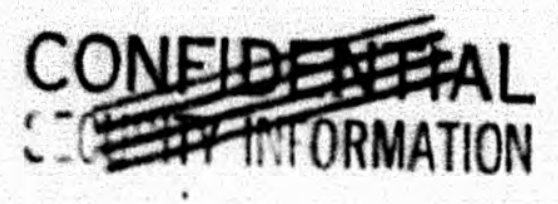




\section{CONFIDISEFAL -4. vCrL.22\%4

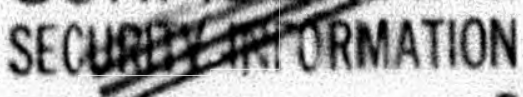 \\ References}

1. Univeraity of California Radiation Laboratory Report, UCRL-1952.

2. W. 1. Linlor and B. Ragent, Bull. Amer. Phye. Soc., 28, 16 (1953), Abotract D2.

3. A. E. Tayler and E. Wood, Phye. Rev, 87. 907 (1952).

4 A. E'. Taylor and E. Wood, Phil. Mag., 44. 95 (1953).

5. B. Ragent and W, I. Linior, Bull, Amer, Phye. Soc, 28, 16 (1953). Ab etract D3. $y$

\section{Figure Caption}

Fig. I The variation with energy of the neutron total crose cection for biemuth and uranium, measured by time-of-fight instrumentation. The errore ohown are otandard deviatione baoed on total counte and on energy chan. nel width. 


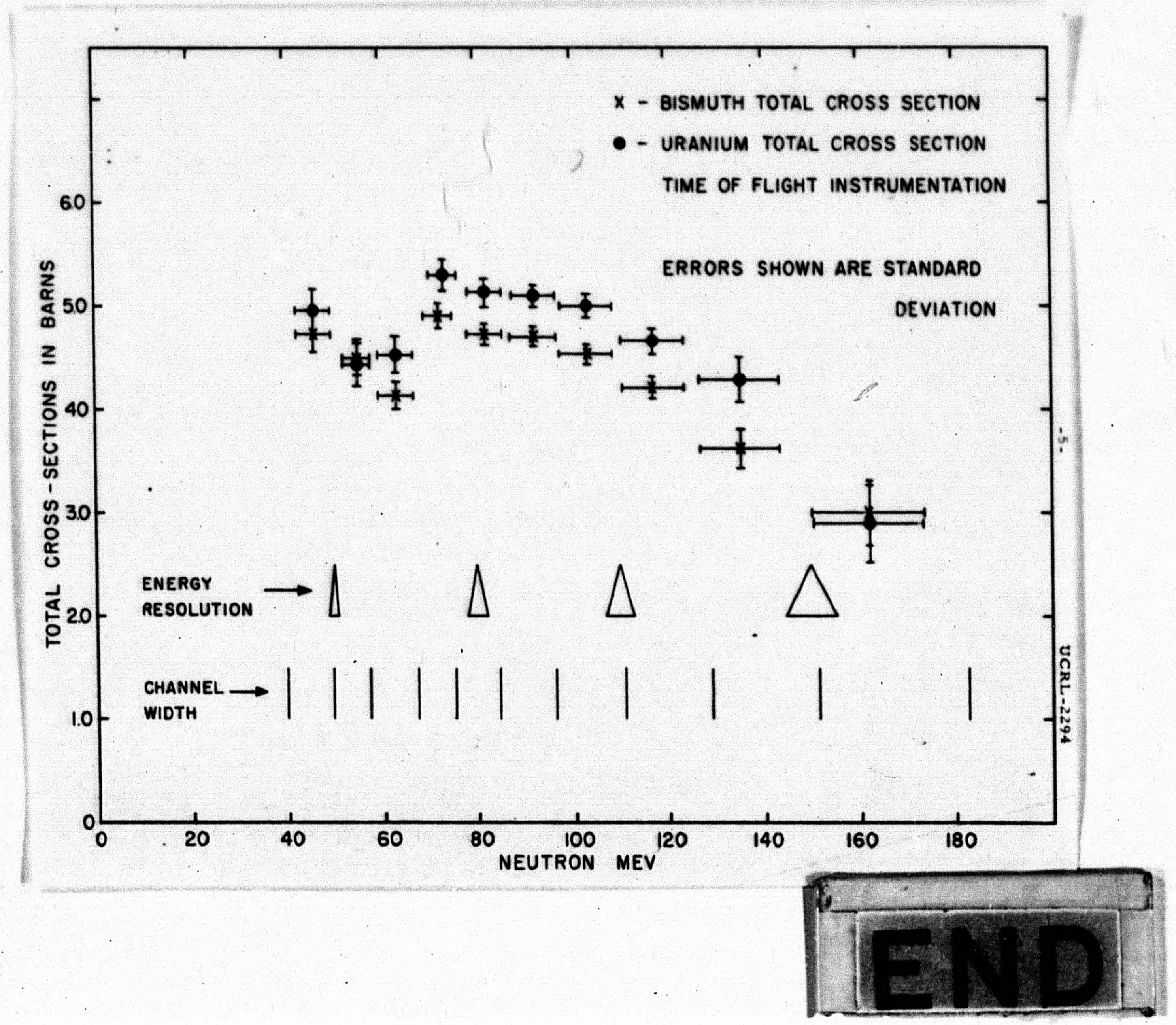

